\title{
El sujeto migrante en la novelística del escritor colombiano Óscar Godoy Barbosa*
}

Fecha de recepción: 6 de febrero de 2018

Fecha de aprobación: 15 de mayo de 2018

\section{Resumen}

Este artículo analiza la obra novelística del escritor colombiano Óscar Godoy Barbosa ${ }^{1}$ desde la perspectiva de la ciudad como espacio caótico que propicia en el sujeto conflictos propios de la contemporaneidad urbana. Duelo de miradas, El arreglo y Once días de noviembre son novelas cuyo desarrollo ocurre principalmente en la capital colombiana: Bogotá; de ello dan cuenta diferentes referencias literales. Los protagonistas de las tres narraciones viven procesos migratorios propios de la Colombia y la América Latina de después de 1950. La sobrepoblación y proliferación de culturas y costumbres, son acentuadas por el afán del progreso. Este tiende a derrumbar rápidamente espacios que han sido cargados de significado para los personajes, afectando la configuración de su identidad y generándoles una condición de desamparo y extravío. Frecuentemente, los personajes vagarán por las calles sin un rumbo fijo, desbordados en su propio conflicto.

Palabras clave: Óscar Godoy Barbosa; ciudad; Bogotá; migración; deriva; caos.

$1 \quad$ Ibagué, 1961. Comunicador social y periodista. Profesor y coordinador del Departamento de Humanidades y letras de la Universidad Central (Bogotá), ganador del Concurso Nacional de Novela "Aniversario ciudad de Pereira" (1999) con su novela Duelo de miradas.

Citar: Fajardo García, J. A. (enero-junio de 2018). El sujeto migrante en la novelística del escritor colombiano Óscar Godoy Barbosa. La Palabra,(32), 219-232. doi: https://doi.org/10.19053/01218530.n32.2018.8176.

\section{Johanna Alexandra Fajardo García}

Estudiante de la Maestría en Literatura de la Universidad Pedagógica y Tecnológica de Colombia, y Licenciada en Lengua Castellana de la Universidad del Tolima.

yolefita@hotmail.com

*Artículo de reflexión derivado de la investigación titulada "Una valoración a la novelística de Óscar Godoy Barbosa", en el marco de los estudios de la Maestría en Literatura de la Universidad Pedagógica y Tecnológica de Colombia. 


\section{la palabra}

\section{The Migrant Subject in the Novels of the Colombian Writer Óscar Godoy Barbosa}

\section{Abstract}

This paper studies the novels of the Colombian writer Óscar Godoy Barbosa from the perspective of the city as chaotic space causing conflict in the subject related to contemporary urban life. Duelo de miradas [Duel of Glances], El arreglo [The Fix] and Once días de noviembre [Eleven Days of November] are novels whose plot is developed most of all in Bogotá, Colombian capital; as can be identified by different literal references. The protagonists of the three novels experience migratory processes common to Colombia and Latin America after 1950. Overpopulation and the proliferation of cultures and customs are accentuated by the rush for progress. This tends to quickly demolish spaces which are loaded with meaning for the characters, affecting the configuration of their identity and generating a condition of abandonment and loss of bearings. Characters frequently drift through the city with no fixed purpose, overcome by their own conflict.

Key words: Óscar Godoy Barbosa; City; Bogotá; Migration; Adrift; Chaos.

\section{Le sujet migrant dans les romans de l'écrivain colombien Óscar Godoy Barbosa}

\section{Résumé}

Cet article analyse le travail romanesque de l'écrivain colombien Óscar Godoy Barbosa du point de vue de la ville en tant qu'espace chaotique qui produit des conflits chez le sujet de la contemporanéité urbaine. Les romans Duelo de miradas, [Duel de regards] El arreglo [L'arrangement ] et Once días de noviembre [ Onze jours de novembre ] se déroulent à la capitale colombienne: Bogotá; ce qui est mis en évidence à partir de citations textuelles. Les personnages principaux des trois récits vivent des processus migratoires types de la Colombie et de l'Amérique- latine après 1950. La surpopulation et la prolifération des cultures et des habitudes sont accentuées par le désir de progrès. Celui-ci detruit rapidement les espaces chargés de sens pour les personnages, tout en modifiant la configuration de leurs identités et produisant, par consequence, une condition d'impuissance et d'égarement. Fréquemment les personnages errent dans les rues sans but précis, débordées par leur propre conflit.

Mots-clés: Oscar Godoy Barbosa; ville; Bogotá; migration; dérive; chaos 
Toda narración literaria transcurre en un determinado espacio y la novela moderna ha optado por elegir como espacio predilecto a la ciudad, lugar capaz de transmitir sus afanes y traumatismos a quienes la habitan. La tradición de esta data de un tiempo más antiguo que el de la novela, puesto que de su origen se habla incluso desde la misma biblia, cuando se menciona en el génesis que "Construyendo para sustraerse a la mirada acusadora de Javé, Caín reconstruye la ciudad como una nueva patria del exilio" (Zarore, 1993, p. 11). De acuerdo con esto, la ciudad siempre ha estado predeterminada para ser un lugar anhelado, a la vez que frustrante y enlazado al caos. En unas ocasiones, es vista como el refugio capaz de acoger en momentos de angustia, aunque en otras pueda ser causante de la misma.

Esa ciudad, en la actualidad, agitada y convulsionada, es propicia para los conflictos. La literatura presencia y recrea este acelerado y caótico ritmo en sus obras. "Especialmente en la segunda mitad del presente siglo, tanto el concepto como la imagen de la ciudad han evolucionado de manera considerable en nuestra literatura, al pasar de la representación del mundo ideal a mundo real y degradado" (Giraldo, 2000, pp. XVII-XVIII). La urbe va imponiendo sus efectos sobre sus habitantes de manera sobrecogedora. "Cualquiera de nosotros, si analiza su comportamiento en la ciudad, se apercibirá [...] de qué increíble conjunto de pequeños mitos, de ritos, de tabús, de complejos positivos y negativos" (Argan, 1984, pp. 221-222) afectan nuestro comportamiento.

La literatura, con sus diferentes tipos de obras, nos puede (o no) permitir dar una ojeada a una determinada sociedad. Por supuesto, "La ciudad no responde a una sola perspectiva y la literatura tiene su aporte al recrearla ya sea fielmente o inventándola, construyéndola o quizá tumbándola a pedazos." (Bernal, 2010, p. 215). Las obras de arte, según su estilo, exaltan o desestiman la influencia de la ciudad con diferentes intenciones, que le corresponde al receptor ampliar.

En Latinoamérica, y específicamente en nuestro país, Colombia, la configuración de la ciudad estuvo condicionada por diferentes factores como el migratorio. Fenómenos como el del desplazamiento causado por la violencia a partir de 1950 , causan una gran afluencia del sector rural al urbano. Allí, convergen diversidad de culturas, intereses, necesidades y tradiciones. La capital colombiana, principalmente, se convierte no solo en refugio de quienes huyen, sino también en oasis de quienes buscan nuevas oportunidades. Expresado en palabras de un estudioso en el tema, fue así como "Explosión demográfica y éxodo rural se combinaron para configurar un fenómeno complejo e incisivo [...] cuyo escenario serían las ciudades elegidas para la concentración de esos inmigrantes desesperados y esperanzados a un tiempo" (Romero, 1999, p. 390).

Novelas como Al diablo la maldita primavera (2002), de Sánchez Baute; Scorpio city (1998), de Mario Mendoza; Sin remedio (1984), de Antonio Caballero; y Los parientes de Esther (1978), de Luis Fayad; entre otras; dan cuenta en sus páginas de las convulsiones, luchas y fragmentaciones de la urbe capitalina. Estas novelas no solo se desarrollan en la gran ciudad, sino que la narran con sus afectaciones y apuros (Valencia Cardona, 2009). También la novelística del escritor Óscar Godoy Barbosa transcurre en la ciudad de Bogotá. A ella llegan sus personajes migrando desde la provincia para establecerse definitivamente.

Su identidad, al igual que la del sujeto migrante en la narrativa colombiana contemporánea (en general), tiende a pensarse como "un sujeto esencial y unitario que es migrante por su propia condición humana más que por las condiciones históricas, sociales y económicas" (Ramírez Gómez, 2008, p. 33). En esta novelística, los personajes no padecen en su migración de un gran cambio en las fron- 
teras geográficas o lingüísticas. Sin embargo, no son personajes estáticos, su migración alude directamente en la construcción de su identidad, los cambios por los que pasan son a nivel interior.

\section{La ciudad tránsito}

Bogotá es la ciudad que, en mayor medida, ha sido receptáculo de muchas otras zonas de Colombia, sobre todo del área rural. Esta ciudad con el tiempo ha llegado a saturarse poblacionalmente debido a la gran afluencia de personas que acuden a su territorio. La mayor causa es la "migración masiva del campo a la ciudad" (Argan, 1984, p. 119) desde 1950, que se relaciona con el fenómeno de la violencia (bipartidista) ${ }^{2}$. No obstante, también hay otros componentes, como el hecho de que la capital es una metrópoli; allí brilla la esperanza del trabajo, el estudio, las influencias, las oportunidades, en resumen, del "progreso".

Esta búsqueda, sin importar el nivel de éxito obtenido, siempre cobrará su precio, en términos económicos o sociales $\mathrm{y}$ siempre en términos emotivos. Cuando alguien se aleja de su espacio de origen, experimenta una transformación de sí. Esto ha sido verificado en estudios en que los migrantes expresan sentimientos contradictorios entre su proceso de desprendimiento frente al de adaptación, como lo comenta Giraldo (2000):

El tema, vinculado en América Latina con el tránsito a grandes o medianas ciudades, mediatizado por el abandono de otros países o de regiones rurales o provincianas (lo que aporta una alta carga emocional), ha evidenciado tensiones y a su vez conflictos de identidad frente a la necesidad de cambio y distanciamiento. (p. 138)

En el nuevo hogar, hay que cambiar las costumbres y extrañando el terruño, la vida del sujeto se torna difícil. Es tanta la desazón de sentirse lejos de su hogar, como lo comenta Cornejo Polar (1996), que siempre el migrante va a acompañar sus triunfos de sentimientos de nostalgia y añoranza (p. 840). $\mathrm{Su}$ identidad tiende a dividirse, busca su estabilidad y felicidad en el nuevo lugar que habita, pero no se desprende totalmente de su lugar de origen.

La ciudad se torna prolífica y diversa, los excesos, el acelere y la individualidad extrema, se convierten en algunas de sus características propias. El sujeto en medio de esta, llega a sentirse abandonado y empieza entonces a vagar en medio del caos urbano perdido en su propio caos interno. Vive un proceso de transformación en el cual ya no reconocerá como propio ni su antiguo hogar ni el actual. "La identidad de la ciudad ha variado de forma sustancial y la relación de pertenencia del personaje entra en crisis hasta convertirlo en visitante precario de una ciudad que fue suya y está dejando de serlo." (Cornejo Polar, 1996, pp. 837-838). Más allá del espacio, lo que se pone en juego es la construcción de la identidad del sujeto. La búsqueda de su lugar en el mundo, termina siendo la búsqueda de sí mismo.

\section{Volar del nido: Duelo de mira- das, Once días de noviembre y El arreglo}

El hecho de partir de casa, afecta de muchas maneras a quien lo vive. Las raíces que un individuo debe desligar para adaptarse a su nuevo hábitat, pueden dejar huella e incluso heridas. En la obra de Godoy Barbosa, encontramos varios tipos o motivos de migraciones, en su mayoría, voluntarias. En todos los casos, llegan a la capital y habrá variables que impulsen en ellos sentimientos de huir, en ocasiones los llevarán a cabo, pero siempre terminarán retornando.

En la novela Duelo de miradas (2000), el joven protagonista parte de su casa para ir a estudiar a Bogotá. Este es un hecho que se presenta, aun hoy, con bastante frecuencia. Luego de

\footnotetext{
2 Periodo de violencia ocurrido en Colombia en el siglo XX entre los partidos políticos Conservador y Liberal.
} 
salir de casa, ya no querrá regresar a la provincia, el visitante se convierte prontamente en ciudadano de la urbe: "Vivo en su casa, cada vez menos nostálgico de las tierras calentanas [...] Mi exilio voluntario prometía ser permanente." (p. 58) Vivía feliz y los esporádicos retornos a casa le permitían reencontrarse, más que con personas y lugares, consigo mismo.

La idea de libertad que la ciudad le brinda al protagonista, es lo que más le seduce "Estar lejos de casa era una ventaja indudable: no rendía cuentas, no tenía ojos en la espalda, bastaba una llamada de vez en cuando a la ciudad del eterno calor para reportar que seguía respirando, que los extrañaba." (p. 66). Este sujeto, personaje principal de la obra, ya había sido exorcizado de la provincia; los afanes, ritos e ideales de la actualidad citadina formaban ahora parte de su vida.

Además de la migración del protagonista, esta obra presenta la de otro personaje: "mi niño". Un adolescente que envían a la ciudad a estudiar su bachillerato. En casa de unos familiares, empieza a descubrir el mundo y su sexualidad. Sin embargo, prontamente es requerido de vuelta "Le daría miedo perder al hijo, con el riesgo tantas veces visto de que se amañó y no volvió nunca, un emigrante más en el torbellino urbano." (p. 122). Este es un miedo que sí se materializa en el caso del protagonista.

"Mi niño", al regresar a casa, ya no es el mismo. Lleva a cuestas experiencias admirables para quienes solo salen de su tierra mediante las historias que este les cuenta. "O cuando te volviste a ver con tus amigos y supiste que habías conocido el mundo como ninguno de ellos." (p. 141). Ambos jóvenes viven la migración en diferente escala $\mathrm{y}$ con diferentes afectaciones. El segundo regresa a casa y su breve experiencia en la ciudad funciona como delantera entre sus amigos. El otro, el protagonista, se construye nuevamente a sí mismo, se interna en las profundidades de la fría capital y su tierra queda en el pasado.

El escritor se vale de la narración en primera persona para transmitir con mayor vivacidad, en esta y en todas las demás situaciones, el sentir del personaje que sabe su retorno como una oportunidad de tomar distancia y demostrar cómo "triunfo y nostalgia no son términos contradictorios en el discurso del migrante" (Cornejo Polar, 1996, p. 840), sino que se integran produciendo un nuevo sujeto.
Adicionalmente, la narración se ve fragmentada por cambios en los narradores, que terminan siendo cuatro y todos en primera persona: el estudiante (personaje protagonista del cual nunca se conoce el nombre ${ }^{3}$ ), Carmenza, Julia y Teresa. Esta lectura "tiende, en ocasiones, a desacomodar al lector mediante un texto en el que intervienen fragmentos y se rompen continuidades" (Gaitán Bayona, 2014).

Por otra parte, en la novela Once dias de noviembre (2015), el protagonista, Guillo, decide migrar de Bogotá. Debido a la separación de sus padres y el posterior fallecimiento de la madre, crea un fuerte resentimiento hacia el padre. Esto se traduce en un intenso deseo por alejarse de allí "Qué me amarraba a la ciudad de la lluvia. [...] No entendiste. Me voy de esta ciudad. Me voy lejos. Y seguí mi camino bajo el aguacero." (p. 129). En parte, se marchaba para aliviar su tristeza; y en parte, se iba para, de algún modo, vengarse contra el padre; esto se transmite en los diálogos con él, siempre breves, siempre cargados de irritación.

Sin embargo, once años después, un giro inesperado lo cambia todo: su padre, Guillermo, queda atrapado en la acción bélica conocida como La toma

3 Este desconocimiento del nombre en el protagonista es analizado, en artículos académicos, con las novelas Simone de Eduardo Lalo (Gaitán Bayona, 2014) y Formas de volver a casa de Alejandro Zambra (Saavedra Galindo, 2017). 
del Palacio de Justicia ${ }^{4}$. Esto mueve toda la estructura vital del personaje y decide regresar a "La tierrita, como dice el viejo Manu. La tierrita me ha extrañado y de repente llama." (p. 114). Hay una personificación en el tratamiento que se da a ese lugar de procedencia que, para el personaje, resulta siendo quien extraña, quien busca. Guillo decide regresar imprevistamente y a su retorno, se encuentra con una nostalgia que no sabía que existía dentro de sí.

No alcanzaba a darme cuenta de los cambios que se operaban dentro de mí a medida que avanzaba. [...] Como se desdibujaban los once años en otros mundos. Más de la tercera parte de mi vida, según los cálculos al calor de la Cachimba. Parecía como si un monstruoso paréntesis se hubiera cerrado de repente, y la vida continuara en aquel espacio (la Séptima) del que nunca había salido. (p. 187).

Igual que en la obra antes mencionada, aquí el autor se vale del recurso de la narración en primera persona para permitirnos conocer las reflexiones íntimas por las que pasa el personaje al sentirse sobreestimulado por el espacio. Los lugares son descritos con su imagen, su olor, sus sonidos, permitiéndole a Guillo recrear y revivir un pasado que había creído carente de valor. «Evocar no es pues, sólo recordar. Es entrar en un proceso fundamental de "resurrección" de momentos y de objetos sin los cuales el hombre perdería toda sensación de identidad y toda seguridad.» (Cruz Kronfly, 1999, p. 170).

Guillo fue uno antes de salir de Colombia, otro viviendo en el extranjero y seguramente será otro más a su regreso a Bogotá. Ya las viejas heridas han perdido importancia frente a la situación que ahora se presenta. Caminar otra vez esos espacios que no sabía que conocía tan bien y que estaban tan gravados en su memoria, lo dejan perplejo. Estas particularidades en su ánimo, con respecto al lugar y al tiempo, se hacen vívidas gracias a la atmósfera descrita:

La memoria es selectiva. A lo largo de once años la Séptima, pero no toda la carrera Séptima sino aquel trayecto del Centro, era la imagen que mejor conservaba de Bogotá. Más que la casa, el viejo barrio, los cines y los parques donde fui feliz. La Séptima en el Centro, con su trazo y su aroma de ciudad vieja. Con su atmósfera tan diferente al resto de la ciudad y de la misma Séptima cuando avanza hacia el moderno norte. Como si la Bogotá del corazón solo habitara en esas pocas cuadras. (p. 188).

El personaje vuelve a transitar lugares que ya conocía, que solía frecuentar hace años, pero que ahora han sido resignificados. Estas calles, como cada lugar que vuelve a visitar, tienen ahora un valor más, una carga emotiva que las transforma y que le provocan múltiples efectos.

Otra migración que se menciona en la novela, es la del padre de Guillo cuando era niño. Tiene que salir de casa, junto con su madre y su tío, en Carmen de Apicalá (Tolima) luego de que asesinaran a su padre para quedarse con su finca, La Estrella, y que incluso amenazaran con matarlo a él. La salida obligada y apresurada de casa no deja tiempo para empacar recuerdos ni para asumir el dolor de la pérdida, pues el peligro es inminente. A pesar de la confusión del momento, para la madre de Guillermo la causa de lo sucedido es clara, todo se debía a la violencia bipartista: "todavía no se hablaba de la rabia entre rojos y azules, que veinte años después incendió a este país, pero algo de eso hubo en el crimen de mi marido." ${ }^{5}$ (p. 220).

Esta es la única migración forzada que se menciona en toda

\footnotetext{
$4 \quad$ Acción ocurrida dentro del marco del conflicto armado en Colombia. El seis de noviembre de 1985, un grupo guerrillero incursiona dentro de las oficinas del Palacio de Justicia tomando como rehenes a todos los que en ese momento se encontraban dentro.

5 Rojos y azules: alusión a la violencia bipartidista en Colombia.
} 
la obra novelística del autor, la más dolorosa y la más costosa. Cobra la vida de una persona y todos los bienes de una familia que luego de su salida, sin nada entre las manos, va a tener que pasar dos años de dificultades $\mathrm{y}$ andanzas hasta encontrar un nuevo lugar en el cual reconstruir su vida. Este éxodo, sin duda dramático, hace que el nuevo lugar de morada esté para la madre (abuela de Gui1lo) amarrado directamente al corazón y no le permita partir de allí jamás "Todo lo que somos se encuentra en Armero 6 . Si nos tenemos que morir, preferimos esa muerte en la tierra de nosotros." (pp. 222-223). En este lugar logra trabajar, comprar una casa y pagar los estudios del hijo en Bogotá.

Por último, en la novela El arreglo (2008), encontramos al migrante en el personaje de Laura. Ella no es bogotana propiamente, aunque de su origen se hacen pocas alusiones. "En esta ciudad no tengo a nadie. [...] sólo me quedan las amistades del trabajo, algunas más de mis tiempos de estudiante, y mis admiradores, como tú los llamas. Paso mucho tiempo sola" (p. 47). En diálogos como este, se manifiesta cómo entre las grandes cantidades de gente que habitan la capital, el sujeto puede sentirse envuelto en la angustia de la soledad. La protagonista llega a Bogotá para estudiar y se quedará allí de manera permanente, asumiendo todos sus costos.

Ahora es habitante de ciudad y las idas de regreso a casa, que son eventuales, funcionan igual que en Duelo de miradas (2000): como un espacio neutro, una toma de distancia que permite reflexionar sobre la vida. La estancia en casa no será definitiva en ningún caso; ahora, Laura es visitante en su propia tierra.

Fin de año en casa, con tantos rostros que la conocen desde niña. Marcar distancia, pensar la decisión que ha venido aplazando. [...] En casa, lejos de Bogotá, de sus montañas, rodeada de risas, de niños, de música, de aromas familiares (p. 86).

Ahora, ver "Su habitación: la misma decoración de sus quince años, la cama, los viejos afiches que ya no le dicen nada" (p. 87), produce sensaciones ambiguas. Su casa ahora le resulta un lugar extraño, ajeno pero seguro. Laura ya no es la misma persona que vivió allí, su vida se mueve ahora bajo las reglas de la urbe, ha cambiado y no solo ella lo sabe, quienes la rodean también: "La entrada de Laura, la prima que vive en Bogotá, será motivo de comentarios, saludos efusivos, lances de antiguos pretendientes." (p. 87).

Asimismo, su vida en Bogotá se somete a una nueva migración. Ya no solo cambia de ciudad, ni de país, sino de continente en busca de dar solución a sus conflictos emocionales. "Londres ha sido como un bálsamo para mi espíritu angustiado" (p. 122). Similar a lo narrado en Once dias de noviembre (2015), la protagonista se aleja en busca de sanar, de olvidar, de superar sus aflicciones. Pronto volverá a Bogotá, pero a diferencia de la novela mencionada, a su regreso encontrará vivas todas sus angustias y contradicciones.

\section{Una brizna en el mar: Duelo de miradas y El arreglo}

Recorrer la capital, sus calles, sus avenidas, suele tener un efecto particular sobre el sujeto. Las calles inundadas de personas, sonidos, imágenes y aromas, pueden propiciar emociones contrarias: por un lado, si hay novedad, pueden aturdir y saturar al transeúnte; por otro, pueden generar el mayor desinterés posible. La ciudad contemporánea, que es el lugar de los afanes, de la inundación comercial y de la indiferencia, consume prontamente en su ritmo a sus habitantes generando nuevas emociones y estados. Aparecen la soledad y la ano-

6 Armero: ciudad del norte del Departamento del Tolima (Colombia) que fue sepultada, con más de 25.000 habitantes, por la avalancha producida por la erupción del volcán Nevado del Ruíz el día trece de noviembre de 1983. 
mia: "Vagar a solas entre la multitud, recibir la mirada anónima $\mathrm{y}$ ejercer en contraprestación equivalente la mirada anónima, esto es precisamente aquello que constituye al transeúnte, que constituye lo urbano" (Cruz Kronfly, 1999, p. 175).

Con facilidad, podemos hacernos la imagen del sujeto que atraviesa las calles, con las manos en los bolsillos, imbuido en su propia situación y preocupaciones, ajeno a lo que sucede a su alrededor, y podemos también imaginar cómo esa imagen se repite de manera exponencial. Hoy, en definitiva, "El ideal moderno de subordinación de lo individual a las reglas racionales colectivas ha sido pulverizado" (Lipovetsky, 2000, p. 8). Las personas viven yendo a la deriva por la gran capital: "La deriva como práctica hace presencia protagónica en la novela urbana y crítica contemporánea en Colombia, en ella los personajes deambulan, construyen a su manera sus propias cartografías urbanas y a menudo sucumben a su propio caos" (Valencia Cardona, 2009, p. 37). Esto se evidencia en dos de las novelas del autor Óscar Godoy Barbosa: Duelo de miradas (2000) y El arreglo (2008).

En la primera novela del autor, Duelo de miradas, el personaje pasa por una tormenta interna, ocasionada por su reciente descalabro emocional. La reiteración del pronombre reflexivo tiene la función de recalcar ese sentimiento de agobio en el personaje que busca palabras para definir su estado emocional, y no encontrando una precisa, se despliega en expresiones que personifican la ciudad: "citadino por convicción. La ciudad me cegaba, me absorbía, me contagiaba, me consumía" (pp. 27-28). Camina por las calles y sube a las busetas sin rumbo fijo, absorto en su dolor y tristeza.

Le hice señas a una buseta y me subí sin saber hacia dónde. Si tenía letrero no lo vi. Debía llamarse Claudia-Tibabuyes o Caludia- San Cristóbal, o tal vez Claudia- La Gaitana. Una ruta cualquiera, una buseta más, llena de pulgas y de una pulga. Una ruta urbana que me trajo la desgracia (p. 29).

El protagonista asume solo su abatimiento, nadie sabe de su pena y él no sabe de las penas de nadie más. "Para variar, no abordamos la acostumbrada buseta sino un taxi moderno, conducido por un hombre taciturno, desentendido del caos amoroso en el puesto de atrás" (p. 123).

Los individuos recorren la ciudad sin aprecio, sin detallarla; la viven en un modo ajeno, es un estar sin estar. "No recuerdo todos los lugares recorridos anoche, Kalimán. Dos bares para amanecidos, múltiples busetas por sectores peligrosos, barrios de fantasmas, avenidas, aguje- ros en el pavimento, al norte, al sur, anduve por toda la ciudad vacío de vida, de intenciones" (p. 164). El personaje protagonista se siente vacío y siente la ciudad y sus espacios carentes de significado. Su modo de expresarlo, además de las reflexiones consigo mismo, incluye los diálogos con Kalimán, un tendero a quien confía todas sus penas.

En la segunda obra publicada por Óscar Godoy, El arreglo (2008), las calles y los lugares que frecuentan los personajes son contados. Para ellos, igual que para los personajes de la novela anteriormente mencionada, lo que importa es la tempestad emocional en la que se encuentran. Los lugares con toda su indumentaria, pasan por momentos, a resultar completamente indiferentes: "La misma agitación del mediodía; los mismos meseros como fantasmas. Poco ha cambiado en Magot en estos años" (p. 124).

Cada quien se ocupa en sus pensamientos y olvida al resto. Así, para algunos, puede resultar que el personaje protagonista está completamente concentrado en algo de su interés, y a otros, parecerles que no se ocupa de nada, pero solo él mismo sabrá cuál es la tormenta que lo consume. Sin embargo, hay ocasiones en las que el protagonista, que es periodista, busca otra perspectiva. Es consciente de ese sentir ajeno del entorno 
inmediato, para él y para otros, y reflexiona al respecto:

Le gusta porque desde el pavimento, sobre las calles que a diario recorre en auto, sin apenas mirarlas, la ciudad adquiere nuevas dimensiones. Lo que en estos domingos lo conmueve es comprobar que la gente sale, que recorren solo o en grupo la ciclovía, con aire festivo, con una inusitada paz, casi impensable para quienes solo conocen la tensa ciudad de entre semana, o para quienes, como él, han visto el otro país, el que se mueve en las sombras. (p. 162).

Se siente cansado, vencido; su visión crítica de la realidad sumada a su infortunio amoroso han logrado hartarlo de la vida "Ya fue suficiente de conquistar la ciudad. Mejor la cama, el periódico, [...] el mundo que conoce, lleno de humo, de café, de discusiones" (p. 164).

La protagonista, por su parte, intenta de muchos modos continuar su vida y superar su fracaso sentimental. Resuelve casarse y salir del país. Ni el matrimonio ni la distancia consiguen darle esa estabilidad emocional que busca. "Vuelvo a sentarme en mi paisaje particular, con toda la intención de escribirte" ( $p$. 124). Laura está en un país extraño, en el viejo continente, sus ojos podrían deleitarse con la riqueza cultural y panorámica del lugar, pero ella opta por encerrarse en sus emociones.

\section{Caos en la ciudad}

La búsqueda y el desarrollo del "progreso" son una empresa que se desarrolla a toda máquina. Por supuesto, eso conlleva sus efectos que se dan a todos los niveles: social, económico, ecológico, cultural, etc. Toda victoria comporta su respectiva derrota. Por ejemplo, la construcción de un túnel es la destrucción de gran parte de una montaña. Resulta que "El progreso inventado de las ciudades produce miseria y destruye la naturaleza, pero a la vez alivia la enfermedad, catapulta las posibilidades del conocimiento y crea alternativas para reparar los daños ocasionados al medio ambiente" (Chaparro Valderrama, 1999, p. 20).

Son frecuentes las evidencias de los costos que la maquinaria del progreso urbano va dejando a su paso. Los cambios en los espacios físicos se traducen también en cambios en la vida de las personas, que pueden generar crisis de identidad.

La literatura expresa y refleja muchas veces las corrientes ideológicas y culturales de un pueblo. Es un espejo en el que se vierten las realidades, los sueños, las frustraciones y las aventuras de toda la humanidad. La literatura cuyo escenario es la ciudad contemporánea latinoamericana, no escapa a esta sentencia de ser resultado de la vida misma, del acontecer cotidiano y de la lucha diaria del habitante dentro de su entorno. (Bernal, 2010, p. 213).

Por obvias razones, la captura que se hace en las páginas literarias no es un testimonio absoluto de la realidad. Siempre estará presente en esas páginas, la mirada del escritor y las miradas de cuantos lectores lleguen a ellas. Por consiguiente, "Al escribir las ciudades o, mejor, al hacer que ellas sean escritas además de vividas, no se puede ignorar lo que ya existe, lo que falta y lo que cotidianamente se pierde o se agrega" (Giraldo, 2000, p. XXV). Así, al momento de la lectura, el sujeto puede generar una visión crítica propia de la obra "que a partir de la ficción narra una realidad con alguna fidelidad, en la que la ciudad y sus zonas poseen nombres propios y pueden ser vivenciales para él" (Bernal, 2010, pp. 180-181).

Los cambios abruptos en el entorno llegan a propiciar agobio y desconcierto. En la medida en que el espacio físico se convierte en referente del pasado ${ }^{7}$, el sujeto se aferra a él y desprenderse puede requerir todo un proceso de duelo. No obstante,

Este tema de lo que significa el territorio urbano en la narrativa es estudiado también, mediante artículo académico, en Calicalibozo de Andrés Caicedo (Guevara, 2014). 
la actualidad derrumba tantos referentes a su paso, y a tal velocidad, que el sujeto tiene que aprender a convivir con ello. De manera consciente, asume todas las transformaciones, aunque, inconscientemente, va acumulando las heridas que esto le genera.

La memoria de un pasado ideal o la referencia a un modelo se sustituye por la relación con el mundo actual que presenta las formas extremas de una civilización signada por la masificación, el anonimato, la violencia cotidiana, la comunicación inmediatista favorecida por los medios, el consumismo capitalista y la nueva cultura (Giraldo, 2000, pp. 131-132).

El individuo se va convirtiendo en testigo de la pérdida de su pasado. Debe adaptarse rápidamente al compás de la sociedad caótica que habita. Esta condición lo supera y lo envuelve en su torbellino, creándole, a su vez, nuevos torbellinos particulares: luchas entre su ritmo y la velocidad de la vida, entre el pasado y el presente, entre él y los demás, entre la soledad y la necesidad del otro, entre su interior y su exterior; que le generan inestabilidad y desconcierto.

La ciudad cambiante: El arreglo y Once días de noviembre

Son muchas las ocasiones en que la literatura nos permite presenciar la transformación de los lugares de nuestra niñez. Los lugares que no habitamos, podemos conocerlos mediante la historia, podemos conocer el antes y el ahora. De este modo, podemos ser partícipes de la medida en que la literatura, y determinada obra en particular, asume el espacio en que se desarrolla. Con respecto a este, hay

casos en los cuales la ciudad no es sólo un telón de fondo, sino actúa y funciona semióticamente como elemento-personaje protagonista, desde distintos ángulos: la especialidad, la mentalidad, la experimentalidad técnica, las dinámicas sociales, las estructuras, los imaginarios. (Valencia Cardona, 2009, p. 11).

Tanto en Once dias de noviembre (2015) como en El arreglo (2008), se narran de manera tenue los cambios que se van ejecutando en la ciudad y cómo son percibidos por los personajes. En ambas novelas, el relato transcurre en más de diez años, por lo cual los cambios son frecuentes y siempre son notados por los sujetos en momentos de tristeza, incertidumbre o frustración. En El arreglo (2008), los protagonistas, Felipe y Laura, van sintiendo el paso del tiempo en los lugares que frecuentan y que, de algún modo, marcan la historia de sus vidas:

-¿Cómo se llama este lugar?
-Dusseldorf. Motel Düsseldorf.

-¿Tu ya lo conocías?

-Mucho antes de casarme. En esa época era un edificio viejo y agradable. Lo tumbaron para construir estas cabañas con sauna y garaje.

-Te trae recuerdos...

-Recuerdos muy antiguos. De amor y de dolor, como todo lo que ocurre en los moteles. (p. 78).

La descripción del espacio permite realizar una lectura del personaje mismo quien, con sus palabras, devela todo el cúmulo de sentimientos pasados y el estado anímico en que se encuentra en ese justo momento. El paso del tiempo se evidencia físicamente en el espacio y moralmente en quienes lo viven. Resulta imperativa la asimilación, adaptarse y continuar superando las nostalgias: "Me cansé de esperarte en Magot... bueno, en el restaurante que pusieron donde quedaba Magot..." (p. 169).

cuando vamos por la calle y constatamos cómo nuestros referentes físicos han sido derruidos de pronto, cómo desaparecen de la noche a la mañana de nuestros ojos, entonces nuestra memoria debe huir a refugiarse solo en la posibilidad de una evocación-resurrección puramente interior y reconstructora, y el sujeto que somos siente que ya no se reconoce ni se refleja en su entorno, que su identidad y su sentido de per- 
tenencia han sido atacados, y se llena de miedos y de inseguridades -muchas veces no confesados- por causa de esa implacable desposesión (Cruz Kronfly, 1999, pp. 170171).

En Once dias de noviembre (2015), los cambios se acentúan en la caracterización de la atmósfera. Con once años fuera del país, el personaje resiente las transformaciones de la ciudad: "El país, ese país que había dejado y que el tiempo acaba por idealizar, ya no era el mismo de mis recuerdos." (p. 192). A la tormenta interior que vive el personaje en la que convergen el rencor por su padre, su orfandad en un país lejano y su soledad, se suman esos miedos y esas inseguridades del regreso a una patria que, aun siendo la suya, se siente ajena. "Al parecer, la conciencia del migrante está más atenta a la fijación de sus experiencias distintas y encontradas que a la formulación de una síntesis globalizadora" (Cornejo Polar, 1996).

Guillo fue un sujeto migrante en Europa y vuelve a serlo, pero ahora en Colombia. La ciudad que lo recibe luego de tantos años, debería ser la misma, pero, de muchos modos, ya no lo es: "Me faltaba redescubrirla aún [...] lo poco recorrido desde los taxis me confirmaba su transformación. No por una simple cuestión de tamaño, sino por el calibre de las fuerzas que albergaba" (p. 224). Necesita encontrar un punto de equilibrio que le permita volver a sentir propia una ciudad en la que se siente extranjero.

La ciudad acelerada: Duelo de miradas, El arreglo y Once días de noviembre

Entre las características de la caótica vida contemporánea en la ciudad, está la velocidad. Este acelere abarca todas las comunicaciones y para el caso, nosotros nos concentraremos específicamente en la comunicación telefónica. Ella permite salvar la distancia de manera inmediata y resolver cuestiones que, por otro medio, tardarían más. Para pensadores como Gianni Vattimo, la importancia relevante en el cambio que vive la humanidad se origina en la fuerte influencia y proliferación de los medios de comunicación. Dice que "esos medios caracterizan a esta sociedad, no como una sociedad más «transparente» más consciente de sí, más «ilustrada», sino como una sociedad más compleja, incluso caótica" (Viviescas \& Giraldo Isaza, 1994, p. 191).

En la novelística completa de este autor, el medio de comunicación del que, en varias ocasiones, dependen angustiosamente sus personajes, es el teléfono. En las tres novelas hay momentos en que el recibir o no una llamada o un mensaje telefónico, genera una completa tem- pestad. En Duelo de miradas (2000), se evidencian situaciones que involucran la comunicación telefónica con los personajes principales y también con los personajes de las historias paralelas. Estos últimos, que son unas jóvenes adolescentes, viven el uso de este como un gran riesgo ante la autoridad que sobre ellas ejercen los adultos: "Imposible alzar el teléfono para decir mentiras con la Hiel en el mismo cuarto" (p. 39).

Para el caso del personaje protagonista, la angustia que desprende este artefacto, es potencialmente mayor: "lo único que tenía de Claudia era aquel número. Nada más. ¿Y si fuera falso? Las dudas me mordían" (p. 83). En torno a este, el personaje vive cantidades absurdas de ansiedad. "Mientras me alistaba para salir al trabajo, aguardaba horrorizado al timbre del teléfono [...] rondé la mesita del aparato maldito, lo miré con ojos de fuego y cedí, cedí, llamé" (p. 98). El joven sufría un frenesí absurdo con respecto a la comunicación telefónica. Situación que no se equiparaba a la misma en relación con su familia. Para él, la comunicación con su región era obligatoria, exclusivamente para garantizar su libertad en la ciudad. Una llamada casual bastaba para tranquilizar la incertidumbre paterna.

En el caso de El arreglo (2008), el teléfono es el medio de con- 
tactarse entre los protagonistas, pues telefónicamente es como son concertados sus encuentros. Es tan importante este medio para los ellos, que su ausencia elimina toda posibilidad de acercamiento: "-Estás furioso... - ¿Cómo no estarlo? ¡Por culpa de ese despido no pude recibir tu llamada, Laura! -A lo mejor nos convenía... -No te entiendo... -Si hubieras pasado al teléfono, no imagino en qué estaríamos hoy" (pp. 145-146). $\mathrm{O}$ hace que el encuentro sea posible, no solo en el momento físico y real, sino que empieza a surtir su efecto desde el momento mismo de la llamada. "-Cuando pasé al teléfono, bastó que dijeras mi nombre para recordarte. Solo tú lo pronuncias así... y se derrumbó mi día..." (p. 136).

El aparato telefónico salvaba distancias enfáticamente emocionales para los protagonistas. Nunca se valieron de él cuando, en la distancia geográfica, pudo ser la única oportunidad de acercamiento; cuando Felipe viajaba por su trabajo, pensaba mucho en Laura, pero jamás pensó en hablar telefónicamente con ella, y cuando ella estuvo en Europa buscaba alejarse totalmente de él para sacarlo de su vida y de su mente, así que tampoco usó este medio como contacto. Ambos se negaron a contactarse de este modo, aunque siempre estuvieron presentes en el pensamiento del otro. En cambio, cuando estaban en
Bogotá, siempre se valían de la comunicación telefónica para entablar la primera aproximación.

Por último, en Once días de noviembre (2015), la comunicación se da en momentos cruciales. El teléfono aquí toma un aire de trascendencia, primero porque se da en el marco de una acción bélica donde es la vida la que está en juego. Segundo, porque permite salvar enormes distancias geográficas. Cuando estallan las bombas en el Palacio de Justicia, Guillermo encuentra la forma de llamar a casa "se inclina y alcanza el auricular. La línea funciona. De inmediato marca el número del apartamento. El timbre suena una y otra vez" (p. 30).

Luego de que Guillo, en el viejo continente, se entera por noticias de lo que sucede, se dispone a averiguar por la suerte de su padre quien trabajó allí:

Cómo preguntar por el nombre tanto tiempo sin pronunciar a una desconocida dulzura que de repente se comunica con mi alma [...] $\mathrm{Y}$ cómo responder sin desmigajarme a ese llanto que se desata de repente, al otro lado del Atlántico y arriba de la cordillera de los Andes, mientras intenta conformar unas, las funestas palabras: -¡Guillo, mi papá está adentro del Palacio. (p. 33).
De esta llamada, deriva la decisión de regresar a Colombia. Lo hace y busca verse con su padre, quien logra salir con vida de aquel percance, pero no está en Bogotá, ha viajado a ver a su madre en Armero; por lo que, otra vez, será el teléfono el medio de conexión entre ambos.

-Adivina quién está aquí.

Tras decidir que finalmente sí pasarían la noche en Armero, y viajarían temprano al día siguiente, Guillermo quiso llamar a Juliana. [...] Incluso una semana atrás, en medio de la batalla, la única llamada que logró hacer desde el bunker de la oficina le permitió escuchar esa voz querida. [...] Guillo, el apelativo familiar que le dieron todos para diferenciarlo del padre, suena como un regalo en la voz alegre y cariñosa de Juliana. Y lo es, por su puesto. El pulso se le acelera. (p. 208).

Una conversación telefónica será el único contacto que Gui1lo, después de once años, y para siempre, tendrá con su padre. Luego de una gran ansiedad y una mezcla de pensamientos, recuerdos y sentimientos, esas breves palabras resolverán cualquier conflicto que pudo existir. Solo el hilo telefónico basta para poner el alma en la boca de los personajes, solo digitar unos números sacará de órbita a estos sujetos en lugares tan distintos de la geografía y de la emotividad. 


\section{Conclusiones}

Bogotá es el escenario urbano al que migran, desde la provincia, los protagonistas de la obra novelística del autor colombiano Óscar Godoy Barbosa. La gran ciudad es el lugar que ofrece a todos, la posibilidad de ejecutar sus proyectos académicos, laborales y profesionales. Sin embargo, el ritmo de la metrópoli sobrepasa al sujeto y se cuela por lo más recóndito de su ser. Provoca efectos muy propios como exceso de ansiedad, soledad y extravío, que son transmitidos, en gran medida, mediante la narración en primera persona.

Los protagonistas de Duelo de miradas, El arreglo y Once dias de noviembre, llegan a la capital colombiana para estudiar (periodismo, publicidad y derecho, respectivamente), pero luego la convertirán en su lugar de residencia. Luego de llegar a Bogotá, ninguno querrá regresar a su región de manera definitiva. Habrá momentos en que desearán huir, pero siempre regresarán. El problema es que la ciudad superpoblada genera en sus habitantes conflictos internos, ya que estos asumen, de manera personal, los acelerados ritmos de la misma.

El proceso de migración deja abiertas ciertas brechas que provocan una sensación de inesta- bilidad, que pone en crisis al sujeto. En medio de su propio desconcierto, empieza a andar por las calles, y por su vida, a la deriva; camina sin un rumbo determinado, buscando algo que no sabe qué es y que obviamente no encuentra. En Duelo de miradas, la deriva se materializa, para el personaje principal, en las rutas de buseta que aborda sin detenimiento alguno. En El arreglo, la deriva se asocia al trabajo, Felipe se sumerge en sus ocupaciones laborales para evitar pensar en su conflicto sentimental mientras transita por las avenidas.

La vida urbana contemporánea resulta caótica. El progreso que se da en las ciudades va arrasando de manera acelerada con esos lugares tan conocidos para el sujeto. Esto causa conflictos de identidad al no sentirse parte de nada o al sentir que lo conocido se va desvaneciendo. En El arreglo y en Once días de noviembre, a medida que van pasando los años, los personajes van estando presentes en los procesos de transformación de la ciudad. Esto se hace visible en las múltiples descripciones mediante las cuales en la obra se narra el espacio, al mismo tiempo que las emociones que despierta en los personajes.

Un elemento que influye de manera determinante en la acele- rada vida citadina, es el acceso a los medios de comunicación. Este autor en su obra hace especial énfasis en el uso del teléfono. El hilo telefónico se convierte para los protagonistas, de toda la obra, en el hilo del cual penden sus vidas de manera momentánea. Los diálogos, a través de este, permiten poner de manifiesto los altos niveles de ansiedad que se producen en los interlocutores.

Esta es la atmósfera urbana propuesta por Óscar Godoy Barbosa en su novelística. Sus personajes, sujetos que habitan la gran ciudad, no viven grandes migraciones geográficas (estas se dan dentro del mismo país) sino internas, el desplazamiento significativo que tienen se da con respecto a la configuración de su identidad. Cada quien se debate en sus propios conflictos en la soledad particular que propicia la metrópoli, siendo testigos de sus acelerados cambios y recordando su procedencia como un lugar para recordar mas no para regresar definitivamente, pues ya son ciudadanos de la urbe. Estos sujetos migrantes, afectados por la gran ola del progreso, viven sus días llenos de ansiedad, desconcierto, nostalgia, incertidumbre $\mathrm{y}$ afán por asimilar los múltiples cambios internos y externos que se viven a diario. 


\section{Referencias}

Argan, G. C. (1984). Historio del arte como historia de la ciudad. Barcelona: Laia.

Bernal, Á. A. (2010). Percepciones e imágenes de Bogotá. Bogotá: Magisterio.

Chaparro Valderrama, J. (1999). Colombia urbana: Una aproximación cultural. Bogotá: Universidad Nacional Abierta y a Distancia-UNAD.

Cornejo Polar, A. (1996). Heterogeneidad no dialéctica: Sujeto y discurso migrantes en el Perú moderno. Revista Iberoamericana, LXII(176-177), 837-844.

Cruz Kronfly, F. (1999). La tierra que atardece. Santa Fe de Bogotá: Planeta - Ariel.

Gaitán Bayona, J. L. (2014). Metaficción y escritura del desastre en Simone, de Eduardo Lalo. La palabra, (24), 70-87.

Giraldo, L. M. (2000). Ciudades escritas. Bogotá: Convenio Andrés Bello.

Godoy Barbosa, Ó. (2000). Duelo de miradas. Pereira: Postergraph.

Godoy Barbosa, Ó. (2008). El arreglo. Ibagué: Pijao Editores - Caza de Libros.

Godoy Barbosa, Ó. (2015). Once días de noviembre. Bogotá: Ediciones el huaco.

Guevara, S. (2014). Ver y ser visto en Calicalibozo. La palabra, (25), 31-41.

Lipovetsky, G. (2000). La era del vacío. Ensayos sobre el individualismo contemporáneo (13 ${ }^{\mathrm{a}}$ ed.). (J. Vinyoli \& M. Pendanx, trads.) Barcelona: Anagrama S.A.

Ramírez Gómez, L. (2008). Sujeto migrante en la narrativa colombiana contemporánea. Cuadernos de literatura, 13(24), 29-46.

Romero, J. L. (1999). Latinoamérica: Las ciudades y las ideas. Medellín, Colombia: Universidad de Antioquia.

Saavedra Galindo, A. (2017). Los nombres de la realidad. Autoficción en Formas de Volver a casa. La palabra, (30), 93-106.

Valencia Cardona, M. A. (2009). La dimensión crítica de la novela urbana contemporánea en Colombia. Pereira: Universidad Tecnológica de Pereira.

Viviescas, F., \& Giraldo Isaza, F. (1994). Colombia: El despertar de la modernidad. Santafé de Bogotá: Ediciones Foto Nacional por Colombia.

Zarore, G. (1993). Metafísica de la ciudad. (J. L. Villacañas, trad.) Valencia: Pretextos Universidad de Murcia. 